\title{
The Willandra Fossil Trackway: Assessment of ground penetrating radar survey results and additional OSL dating at a unique Australian site
}

\author{
Michael C. Westaway ${ }^{1,2}$, Matthew L. Cupper ${ }^{3}$, Harvey Johnston ${ }^{4}$ and Ian Graham ${ }^{5}$
}

\begin{abstract}
This paper presents some results of a ground penetrating radar survey conducted to establish the extent of the Willlandra Fossil Trackway, and further mapping of the footprints and intermingled tracks. In addition, it includes a refinement of the age range of the trackway, through further OSL dating, to between 19,000 and 20,000 years ago. Finally, it also provides a discussion of the geochemical composition of the trackway.
\end{abstract}

\section{Introduction}

Fossil footprints have been reported from near Lake Garnpung in the Willandra Lakes region in southwestern New South Wales (NSW), Australia (Webb et al. 2006) (Figure 1). The site consists of at least 26 human fossil trackways (individual sets of footprints), numbered T0-T26, as well as individual human footprints not linked to trackways, and the footprints of marsupials and birds. It is the first such fossil trackway site documented in Australia, and as such represents a very important record of a rare site type.

The Willandra Lakes system comprises a series of now-dry lake basins in the semi-arid interior of southeastern Australia that last contained water around 8000 years ago (Bowler 1998). The footprints are impressed into a hardpan unit located within dunes between Lakes Garnpung and Leaghur; approximately $820 \mathrm{~m}^{2}$ of the surface of the hardpan has been exposed by erosion and excavation (Figure 2a). Originally, a total of 563 human footprints in 23 trackways were reported and previous publications have discussed the morphology, stature, weight, speed and alleged finger markings of the people responsible for them (Franklin and Habgood 2009; Webb 2007; Webb et al. 2006). Following investigation, the site was reburied and its location remains largely hidden to ensure its ongoing protection, with a regular monitoring program by NSW National Parks and Wildlife Service (NPWS) staff to ensure that it is appropriately conserved. In order to provide the public with an understanding of the site, a replica developed from digital scan data has been constructed at the Mungo National Park Visitor Information Centre.

In this paper we provide further contextual information relating to the site's environment, refining the age of the footprints to between 19,000 and 20,000 years ago. In addition,

\footnotetext{
${ }^{1}$ Centre for Environmental Futures, Griffith University, 170 Kessels Road, Nathan Old 4111, Australia <m.westaway@griffith.edu.au>

2 Cultural Environments Program, Queensland Museum, PO Box 3300,

South Brisbane Qld 4101, Australia

${ }^{3}$ School of Earth Sciences, The University of Melbourne Vic. 3010, Australia <cupper@unimelb.edu.au>

${ }^{4}$ NSW Office of Environment and Heritage, PO Box 318, Buronga NSW 2739, Australia <harvey.johnston@environment.nsw.gov.au>

${ }^{5}$ School of Biological, Earth and Environmental Sciences, The University of New South Wales, Sydney NSW 2052, Australia $<$ i.graham@unsw.edu.au>
}

we present further detail of the trackway mapping and revise the total number of footprints present, as well as assessing data from a ground penetrating radar (GPR) survey of the site commissioned for the NSW NPWS (Speer et al. 2006).

\section{Depositional Environment}

The hardpan unit in which the footprints occur is approximately $150 \mathrm{~mm}$ thick and comprises thin $(<10 \mathrm{~mm}$ thick) laminae of magnesitic silty clay. The western edge of the hardpan is indurated and stable but the eastern edge is soft and disintegrating.

\section{Sedimentary Analysis}

Webb et al. (2006) suggested that the hardpan unit was an aeolian deposit. They invoked a depositional model whereby fine-grained aggregates of carbonate minerals and silty clays had blown onto the site from the shore of an adjacent saline lake. To test this proposition, samples of the hardpan in which the trackway occurs were examined using powder $\mathrm{x}$-ray diffraction and further analysed using Siroquant (version 2.5) and scanning electron microscopy (SEM) (AMBS 2008). Coupled with the examination of petrographic thin-sections (by author IG), results show the hardpan is comprised of thin laminae of sandsized magnesitic and silty clay pellets. Those layers near the surface of the unit contain silty clay cemented with magnesite. It is uncertain whether this cementation is primary, due to precipitation from magnesium-rich water ponded at the site, or caused by more recent dissolution and recrystallisation during diagenesis (Figure 3). The footprints of people, marsupials and birds crossing the hardpan could have been impressed during ponding, and the moulds preserved by subsequent magnesite cementation. Alternatively, rain events may have sufficiently moistened a pre-existing magnesitic silty clay layer to enable casting to occur.

Mineral composition varies across the hardpan, with abundant quartz, magnesite, ferroan (iron-rich) magnesite and hydromagnesite, and lesser amounts of illite and kaolinite, in the western part. In contrast, the eastern section is dominated by magnesite and ferromagnesite, with minor illite, kaolinite and quartz. As a consequence of the differing mineral composition, the preservation of the footprints differs substantially across the hardpan surface.

Magnesite, ferromagnesite and hydromagnesite form by precipitation from water in which carbon dioxide has dissolved magnesium-bearing minerals. Their deposition in inland evaporite lakes has been documented where groundwater flows through mafic terrains (e.g. Pueyo Mur and Inglés Urpinell 1987; Renaut 1993; Warren 1990; Wright 1999). Such underlying geology has not previously been documented in the Willandra Lakes and magnesitic evaporites have not been reported elsewhere in the region. 

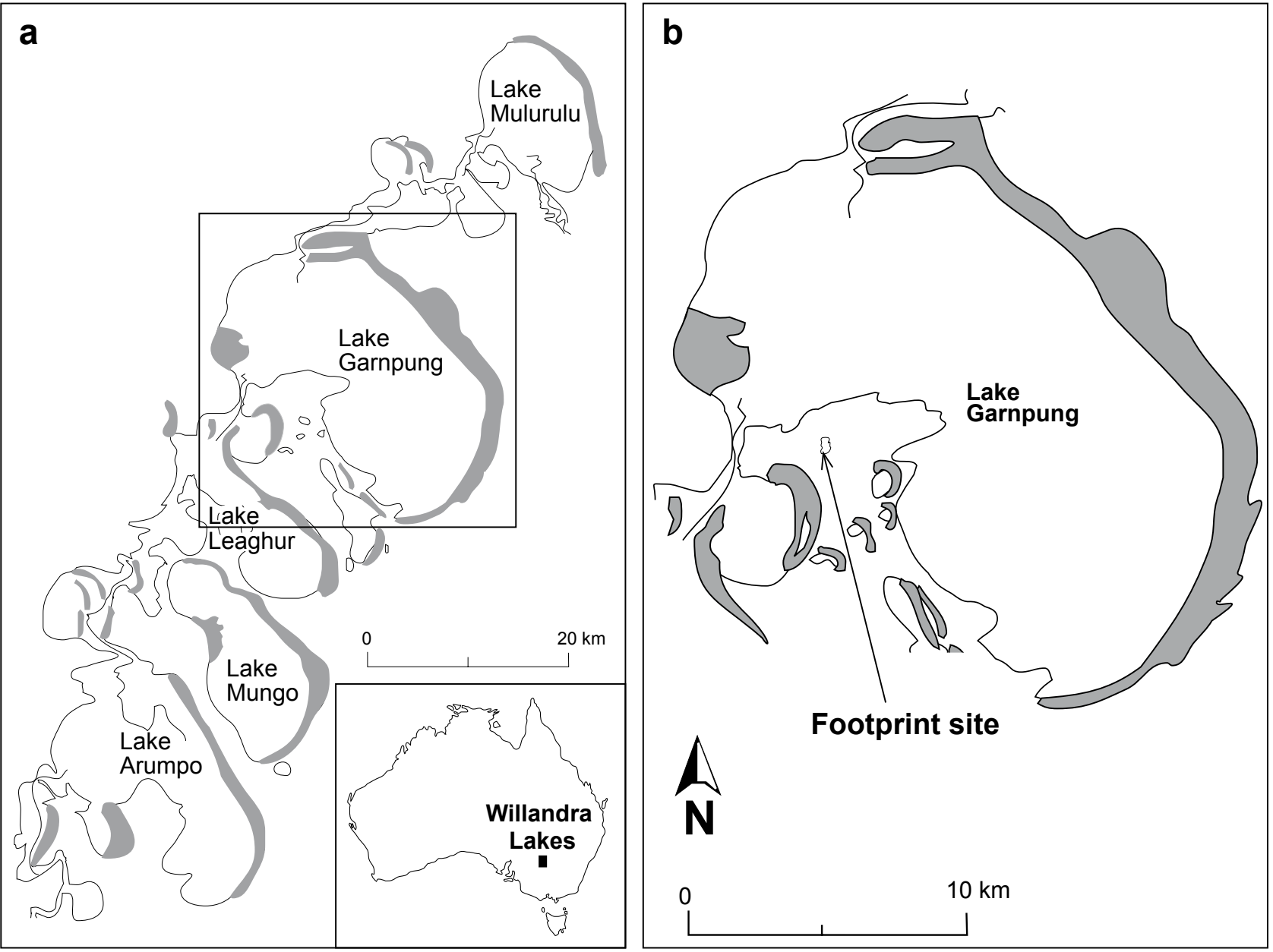

Figure 1 (a) General locality map and (b) Detailed map of Lake Garnpung showing the approximate location of the fossil trackways.

\section{GPR Survey}

In order to assess the extent of the hardpan beneath the adjacent dune, a GPR survey was commissioned (Speer et al. 2006). The survey used $1.5 \mathrm{GHz}, 900 \mathrm{MHz}$ and $2200 \mathrm{MHz}$ ground-coupled radar antennae, proving resolution of $0.5 \mathrm{~m}, 1.8 \mathrm{~m}$ and $7.4 \mathrm{~m}$, respectively. Radio pulse velocity was calibrated from a test pit within the dune. The survey was conducted over an area some $250 \times 180 \mathrm{~m}$ to the north and east of the hardpan. Data profiles were collected in a grid that focused on areas close to the exposed hardpan. A $50 \times 25 \mathrm{~m}$ area was sampled in $5 \mathrm{~m}$ squares, $150 \times 150 \mathrm{~m}$ was sampled in $10 \mathrm{~m}$ squares, and $100 \times 130 \mathrm{~m}$ was sampled in $25 \mathrm{~m}$ squares.

High amplitude responses have been interpreted as clay layers, with a total of eight distinct layers identified. The results indicate that the trackway hardpan — the 'layer of interest'—extends $70 \mathrm{~m}$ to the east and $30 \mathrm{~m}$ to the north under adjacent dunes, and at least $2180 \mathrm{~m}^{2}$ remain buried beneath overlying aeolian sands (Figure 4). The hardpan dips gently to the east and the lowest point is approximately $40 \mathrm{~m}$ east and $1.4 \mathrm{~m}$ below the visible trackway surface. It is possible that this was a depression that ephemerally retained water, as perched soaks where rain water ponds on hardpans are common within the interlake areas of the Willandra today. An additional feature to the north of the site identified in the GPR survey was originally interpreted by Webb (2007) as a gully or possible creek, but its slope has a gentle gradient and we argue that it more likely represents natural dune bedding.
A series of closely spaced high resolution GPR profiles, using a $1.2 \mathrm{GHz}$ antenna, were also measured over $3 \times 3 \mathrm{~m}$ in an attempt to trace one particular set of footprints (T14) east into the overlying dune. Three anomalous signatures were detected beneath the adjacent blanketing dune, 95-150 mm below the surface. Speer et al. (2006) have speculated that these may be caused by the depression of footprint casts and the compaction of the underlying sediment. However, on the basis of location, step length and sub-surface depth, we argue these signatures must be discounted as a continuation of T14. The signatures may be a continuation of T0 that ends $6 \mathrm{~m}$ to the south; the step length of the possible footprints is around $1.4 \mathrm{~m}$, within the range of T0 step lengths $(1.24-1.45 \mathrm{~m})$. Whether or not these anomalies are indeed footprints will only be resolved by excavation.

\section{Age of the Hardpan Unit}

Webb et al. (2006) bracketed the age of the hardpan layer by dating quartz sand from over- and underlying units using optically stimulated luminescence (OSL). They reported a sandy unit $0.5 \mathrm{~m}$ beneath the hardpan to be $23,000 \pm 1200$ years old (GP03) and sediments $0.4 \mathrm{~m}$ and $0.01 \mathrm{~m}$ above as being 19,400 \pm 1100 (GP02) and 19,200 1900 years old (GP04), respectively.

We used OSL to date the hardpan directly and also obtained additional samples from the bounding units (Table 1). A sample from the middle of the hardpan produced an age determination of $19,800 \pm 1200$ years (GP05). Laminated pale 


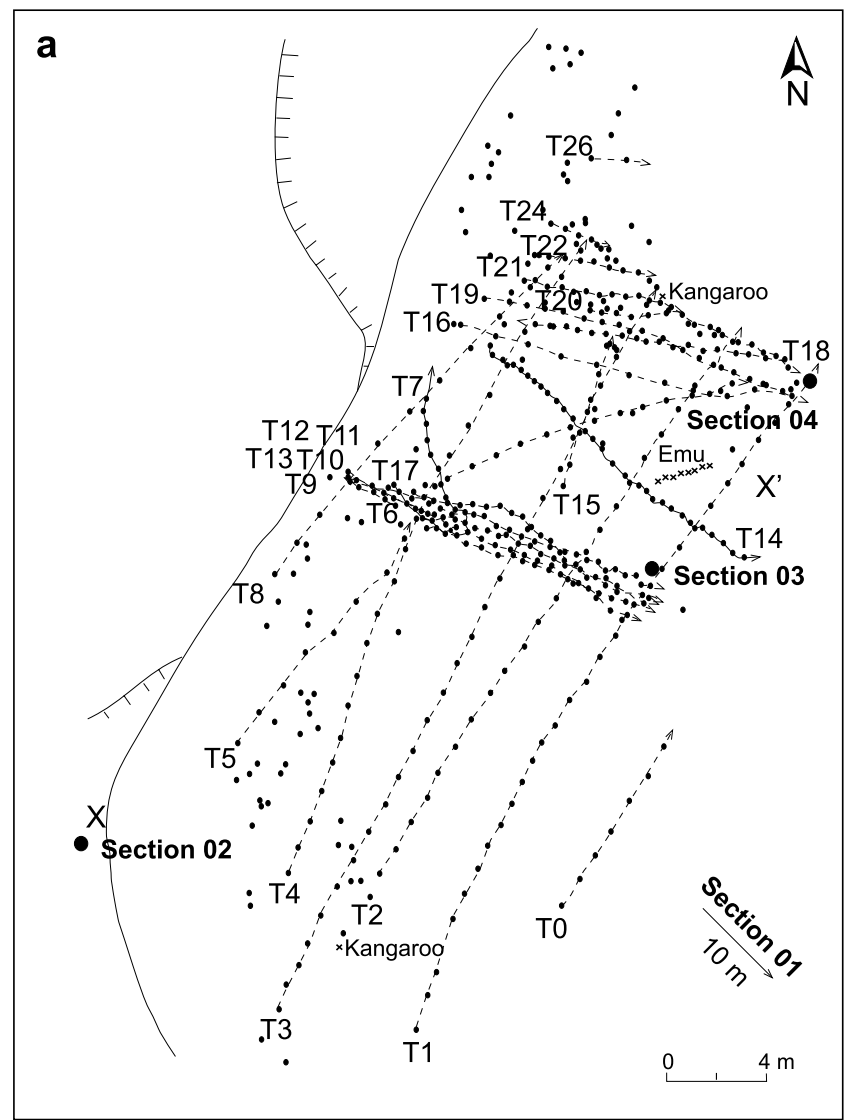

b

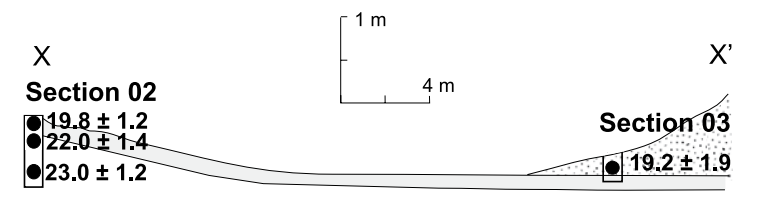

C

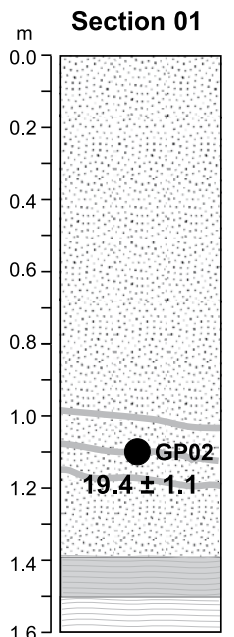

Pale yellow fine sand

Diffuse pale grey

clayey sand laminations

Laminated pale grey clayey sand

Laminated white silty clayey hydromagnesite horizon
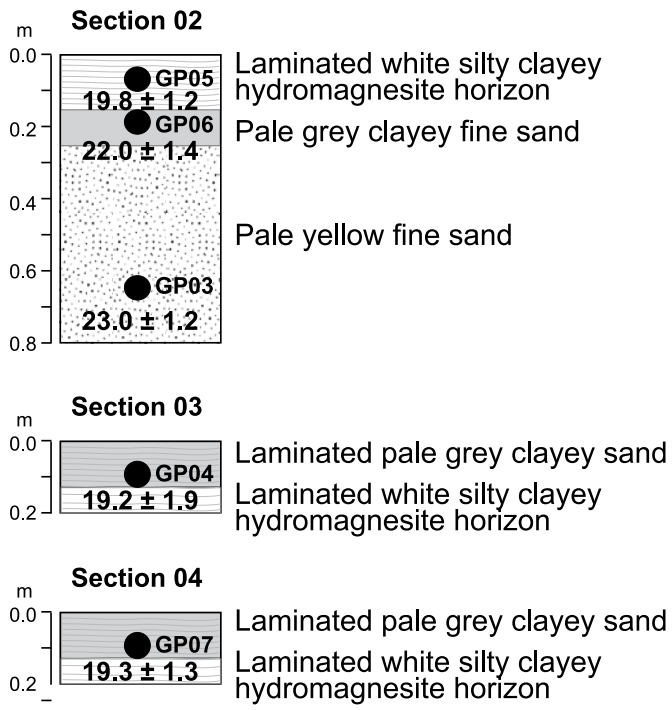

Figure 2 (a) Willandra Fossil Trackway Site plan (note that T25 is located $110 \mathrm{~m}$ to the west and is not shown) (b) Site section and (c) Site stratigraphy and ages.

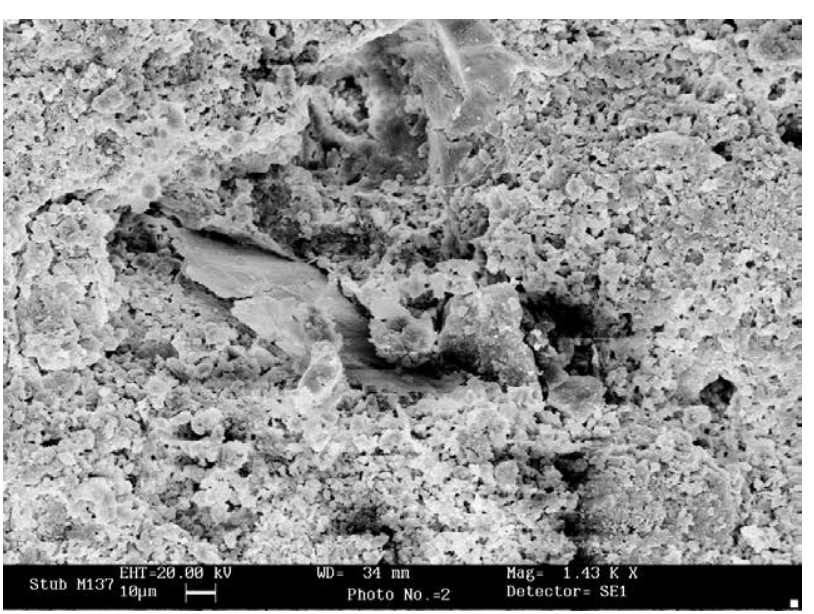

Figure 3 SEM image of the footprint-bearing sediment showing its fine-grained nature and relatively high porosity and permeability in Sample G4, beside Section 04. Siroquant (modal\%) analysis in this sample is magnesite $88 \%$, illite $6 \%$, kaolinite $3 \%$, and quartz $3 \%$ (image by Sue Lindsay, Australian Museum). grey clayey sand immediately above the footprints, in a similar

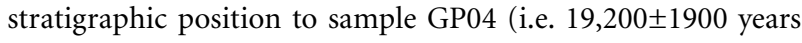
old; Webb et al. 2006), was revealed to have been deposited $19,300 \pm 1300$ years ago (GP07). Pale grey clayey fine sand immediately below the base of the magnesitic silty clay unit is dated to $22,000 \pm 1400$ years old (GP06). These additional ages show that the hardpan was deposited, and the footprints made, around $19,000-20,000$ years ago.

\section{Additional Mapping and Interpretation of the Footprints and Trackways}

The previously published site maps of the trackway (Webb 2007; Webb at al. 2006) were based on field surveys and mapping conducted in 2004 and 2005 using a Sokkia Electronic Total Station. Further mapping of the site in 2006, along with digital scanning of the ground surface and photography (Ogleby 2007), has revealed additional details of the tracks and peoples' movement patterns. A total of 533 footprints have now been mapped and the majority of these have been digitally scanned and the images georectified on to site plans. This number is smaller than the ca 563 footprints reported by Webb (2007), as we only include mapped and photographed locations with clearly defined 

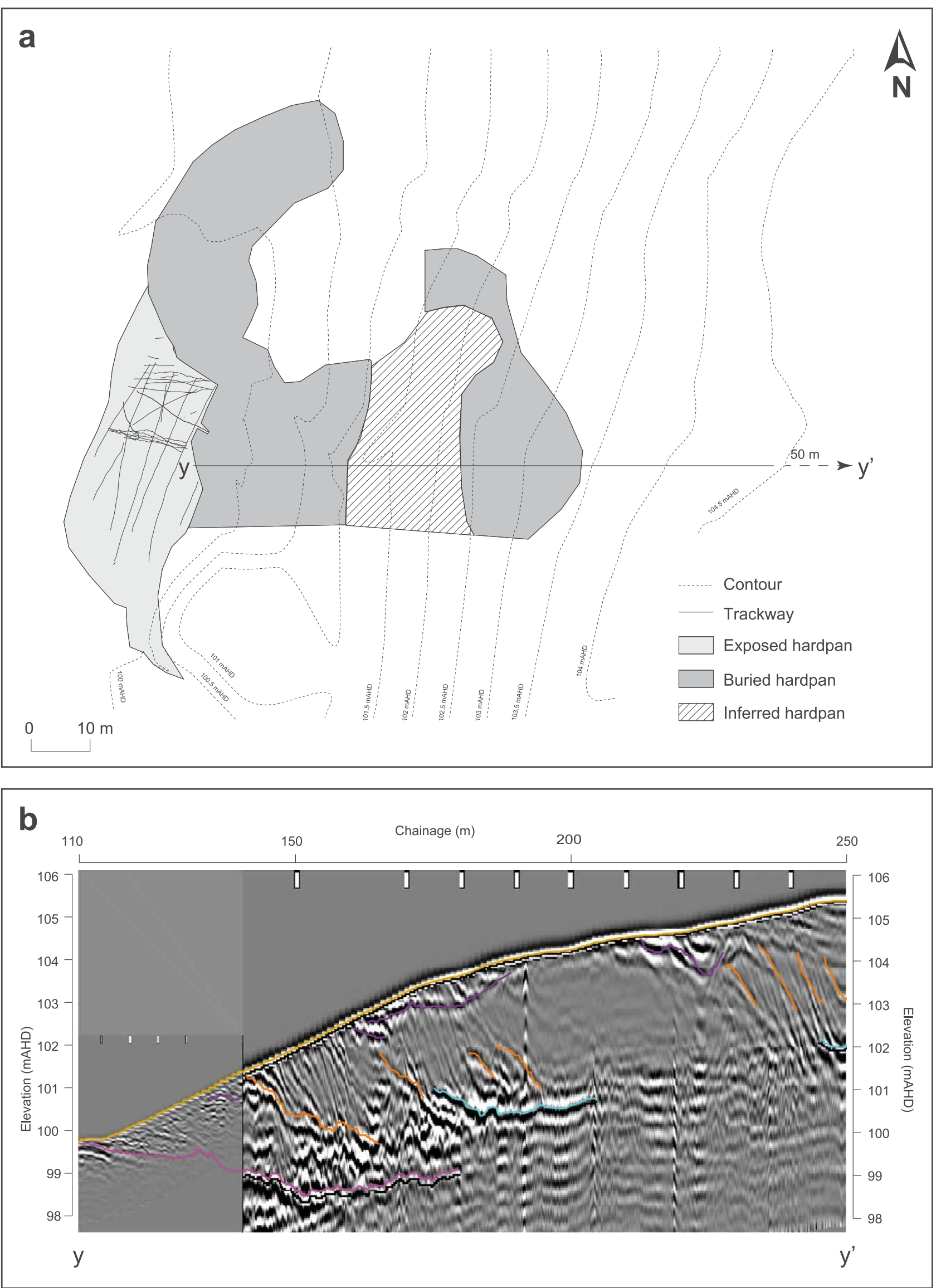

Figure 4 (a) Site plan showing the GPR results, buried hardpan and inferred hardpan to the east and north of the exposed hardpan with tracks (b) GPR cross-section through y - y' from Speer et al. (2007). The hardpan is indicated by the purple line on the lower left of the profile and represents the inferred extent of the magnesitic silty clay layer that contains the footprints. 


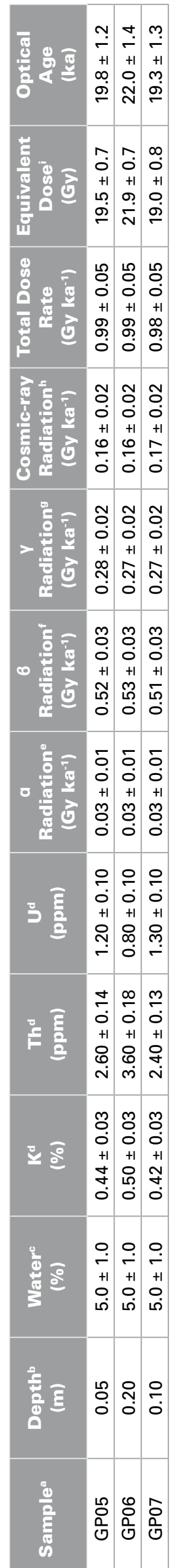

footprints that showed evidence of either a complete footprint outline, the toes and ball of the foot, or the ball and heel of the foot. The surface contains many indistinct depressions that do not meet these criteria; while these depressions may represent eroded or incomplete footprints, they have not been included in this analysis.

Of the 533 footprints, 405 have now been matched into 26 trackways; these include a number of amendments to the previous trackway mapping. Three new tracks have been identified: T24 (comprising four footprints) and T26 (comprising two footprints) are located at the northern edge of the visible hardpan. New track T25 is located in the lowest part of the swale, $110 \mathrm{~m}$ to the west of the main concentration of footprints. An additional five prints each have also been added to tracks T5 and T22. As such, there remain 128 isolated footprints that have not been linked to tracks.

Tracks T6 and T11 have been published as two separate individuals (Webb et al. 2006). Both contain small prints, approximately $200 \mathrm{~mm}$ in length, with very similar step, stride and footprint lengths. These two tracks are aligned and we argue they are likely to be from the same individual. Tracks T7 and T14 may also be different parts of the one individual's track: both are small, possibly child-sized footprints, approximately $160 \mathrm{~mm}$ in length. T7 is the most sinuous track on the site, following a meandering path initially heading in a southeasterly direction, then veering towards the northwest before disappearing. T14 then commences from the northwest and travels to the southeast. Together T7 and T14 comprise 63 footprints and analysis of the stride length reveals a juvenile variously walking, stopping, running and then briskly walking.

The superimposition of individual tracks at a number of locations indicates the complex sequence of the group's movement (Table 2). For example, one sequence of superimpositions shows footprints of a large adult running to the north (T2), overprinted by two smaller tracks walking east (T11 and T13). These footprints are in turn covered in places by those of a large adult (T4) hopping to the north on the right foot only. Another sequence shows an adult walking east (T10), followed by an adult running north (T3) and then a juvenile walking east (T12).

A possible indicator of the seasonal timing of when the tracks were created is provided by a series of eight juvenile emu prints at the site (Figure 2). Based on foot measurements of modern emus, those at the site are estimated to be from 50-70 day old chicks (Stephen Davies pers. comm. 2006). Presently, emus mainly lay eggs in autumn between March and May (Davies 2002), although they also regularly nest after heavy rain events; incubation averages 56 days, suggesting that the prints may have been made in winter or early spring (i.e. between June and October).

\section{Conclusions}

In this paper we have provided additional information on the Willandra Fossil Trackway, the only such archaeological site of its type published in the Australian record. The Willandra Fossil Trackway provides a novel record of Pleistocene Australians existing in the Willandra landscape at the peak of the Last Glacial Maximum, possibly during winter. Further sedimentary research at the site has revealed a clearer understanding of the likely natural 


\begin{tabular}{|c|c|c|}
\hline Event Order & Sequence 1 & Sequence 2 \\
\hline 1st & T2 & T10 \\
\hline 2nd & T11 and T13 & T3 \\
\hline 3rd & T4 & T12 \\
\hline
\end{tabular}

Table 2 Sequence of superimposed tracks.

site formation processes responsible for creating this unique site. Understanding this contextual data is important for any future interpretation, and indeed conservation work, on the trackway. OSL analysis has refined our understanding of the age range of the site, confirming its age at 19-20,000 years BP. Reassessment of the GPR results has indicated that a number of features previously identified as a buried creek and a continuation of a trackway are more likely to represent less dramatic features.

\section{Acknowledgements}

We are grateful for the support of the Willandra Lakes Aboriginal Elders and custodians for allowing us to undertake this research. Representatives of the Willandra Lakes Traditional Tribal Groups were directly involved in the second season of excavation at the trackway site. The GPR investigation and geochemical analysis of the magnesite claypan was funded by the NSW NPWS through the encouragement of Steve Millington. Funding was also provided by the Australian Commonwealth Department of Environment, Water and the Arts. Professor Stephen Davies (Curtin University) is thanked for examining images of the emu prints and providing access to unpublished measurements of emu foot lengths.

\section{References}

$\overline{\text { Adamiec, G. and M.J. Aitken } 1998 \text { Dose rate conversion factors: Update. Ancient }}$ TL 16:37-50.

Aitken, M.J. 1998 An Introduction to Optical Dating: The Dating of Quaternary Sediments by the Use of Photon-stimulated Luminescence. Oxford: Oxford University Press.

AMBS 2008 GL7 Fossil Trackway Archaeological Management Plan. Mungo National Park Willandra Lakes World Heritage Area. Unpublished report prepared for the Department of Environment and Climate Change.

Bowler, J.M. 1998 Willandra Lakes revisited: Environmental framework for human occupation. Archaeology in Oceania 33:120-155.

Bowler, J.M., H. Johnston, J.M. Olley, J.R. Prescott, R.G. Roberts, W. Shawcross and N.A. Spooner $2003 \mathrm{New}$ ages for human occupation and climatic change at Lake Mungo, Australia. Nature 421:837-840.

Bowler, J.M., R. Gillespie, H. Johnston and K. Boljkovac 2012 Wind v. water: Glacial maximum records from the Willandra Lakes. In S.G. Haberle and B. David (eds), Peopled Landscapes. Archaeological and Biogeographical Approaches to Landscapes, pp.271-96. Terra Australis 34. Canberra: ANU E Press.

Davies, S. 2002 Ratites and Tinamous. Oxford: Oxford University Press.

Galbraith, R.F., R.G. Roberts, G.M. Laslett, H. Yoshida and J.M. Olley 1999 Optical dating of single and multiple grains of quartz from Jinmium rockshelter, northern Australia: Part I, experimental design and statistical models.
Archaeometry 41:339-364.

Franklin, N. and P.J. Habgood 2009 Finger markings and the Willandra Lakes Footprint Site, southeastern Australia. Rock Art Research 26:199-203.

Mejdahl, V. 1979 Thermoluminescence dating: Beta-dose attenuation in quartz grains. Archaeometry 21:61-72.

Murray, A.S. and R.G. Roberts 1998 Measurement of the equivalent dose in quartz using a regenerative-dose single-aliquot protocol. Radiation Measurements 29:503-515.

Murray, A.S. and A.G. Wintle 2000 Luminescence dating of quartz using an improved single-aliquot regenerative-dose protocol. Radiation Measurements 32:57-73.

Prescott, J.R. and J.T. Hutton 1994 Cosmic ray contributions to dose rates for luminescence and ESR dating: Large depths and long-term time variations. Radiation Measurements 23:497-500.

Ogleby, C. 2007 Laser Scanning of the Fossilised Human Trackways, Willandra Lakes World Heritage Area. Unpublished report prepared for the NSW National Parks and Wildlife Service.

Pueyo Mur, J.J. and M. Inglés Urpinell 1987 Magnesite formation in recent playa lakes, Los Monegros, Spain. In J.D. Marshall (ed.), Diagenesis of Sedimentary Sequences, pp.119-122.Geological Society Special Publication 36. London: Geological Society Publications.

Renaut, R.W. 1993 Morphology, distribution and preservation potential of microbial matsin the hydromagnesite-magnesite playas of the Cariboo Plateau, British Columbia, Canada. Hydrobiologia 267:75-98.

Speer, J., H. Skeen and S. Williams 2006 Ground Penetrating Radar Investigation to Delineate the Possible Extent of the Pleistocene Clay Layer Containing Human Footprints Within the Willandra Lakes Region, New South Wales. Unpublished report prepared for GBG Australia.

Stone, T.N. and M.L. Cupper 2003 Last Glacial Maximum ages for robust humans at Kow Swamp, southern Australia. Journal of Human Evolution 45:99-111.

Thorne, A., R. Grün, N.A. Spooner, G. Mortimer, J.J. Simpson, M. McCulloch, L. Taylor and D. Curnoe 1999 Australia's oldest human remains: Age of the Lake Mungo skeleton. Journal of Human Evolution 36:591-612.

Warren, J.K. 1990 Sedimentology and mineralogy of dolomitic Coorong Lakes, South Australia. Journal of Sedimentary Petrology 60:843-858.

Webb, S. 2007 Further research of the Willandra Lakes fossil footprint site, southeastern Australia. Journal of Human Evolution 52:711-715.

Webb, S., M.L. Cupper and R. Robins 2006 Pleistocene human footprints from the Willandra Lakes, southeastern Australia. Journal of Human Evolution 50:405-413.

Wright, D.T. 1999 The role of sulphate-reducing bacteria and cyanobacteria in dolomite formation in distal ephemeral lakes of the Coorong region, South Australia. Sedimentary Geology 126:147-157. 